\title{
Criatividade na formação e atuação do professor do curso de Letras
}

\author{
Criatividade no curso de Letras
}

\author{
Zélia Maria Freire de Oliveira \\ Eunice Maria Lima Soriano de Alencar
}

\begin{abstract}
Resumo
A pesquisa investigou como a criatividade era tratada na formação e atuação do professor do Curso de Letras. Foram entrevistados 20 professores de duas instituições de educação superior particulares e uma pública de uma cidade da região centro-oeste do Brasil e foi utilizada a análise de conteúdo para tratamento dos dados. Os resultados indicaram que os professores atribuem importância à criatividade no mundo atual; acreditam no potencial criativo de seus alunos; têm noção sobre criatividade, embora com dificuldade para defini-la; valem-se de vários procedimentos pedagógicos que a facilitam, embora não os utilizem de forma intencional; não sentem necessidade de uma disciplina específica sobre criatividade, percebendo-a mais como procedimento pedagógico; não tiveram em sua formação, de modo geral, informações sobre criatividade, nem tampouco em oportunidades de atualização; lembram-se de poucos professores criativos em sua própria formação e apontaram várias barreiras à promoção da criatividade em sala de aula.
\end{abstract}

Palavras-chave: criatividade; professores; medida.

\section{Creativity in the Linguistics course and the professor's formation and performance}

\begin{abstract}
This study investigated how creativity has been worked upon in the Linguistics Course. Twenty professors from two private and one public higher education institutions in a city from the central west of Brazil were interviewed. Content analysis was employed to analyze the answers given by the professors' enterviews. The results indicated that the professors recognized the importance of creativity in the current world; they believed in their student's creative potential; they had difficulty in defining creativity and they used various pedagogical procedures they believed to foster creativity, even though they did not do it intentionally. The professors did not perceive the need for a specific course on creativity and they saw it more as a pedagogical procedure. Furthermore, they had not had any formal instruction on creativity either on their undergraduate program or in follow up courses. They remembered few creative professors and pointed out several obstacles to the implementation of creativity in the classroom.
\end{abstract}

Keywords: creativity; college teachers; measurement.

\section{Creatividad en la formación y actuación del profesor del curso de Letras}

\section{Resumen}

El estudio investigó como la creatividad era tratada en la formación y actuación del profesor del Curso de Letras. Fueron entrevistados 20 profesores de dos instituciones privadas y una pública de educación superior de una ciudad de la región centro-oeste del Brasil, y fue utilizado el análisis de contenido para el tratamiento de los datos. Los resultados indicaron que los profesores le atribuyen importancia a la creatividad en el mundo actual; creen en el potencial creativo de sus alumnos; tienen noción sobre creatividad, pese a también tener una cierta dificultad para definirla; utilizan varios procedimientos pedagógicos que la facilitan, pese a no hacerlo de forma intencional; no sienten necesidad de una disciplina específica sobre creatividad, percibiéndola más como un procedimiento pedagógico; en su formación, de manera general, no tuvieron informaciones sobre creatividad ni oportunidades de actualización; se recuerdan de pocos profesores creativos en su propia formación y apuntaron varias barreras a la promoción de la creatividad en clase.

Palabras clave: creatividad; profesores; medida. 


\section{Introdução}

O momento atual da História possui características bem peculiares que exigem cada vez mais criatividade dos cidadãos para buscarem soluções aos inúmeros problemas. São incertos os desafios oriundos de um tempo de globalização, de mundialização da cultura, de sociedade em rede, de novas ciências e áreas do saber, de deslocalização e de desfragmentação da produção, características essas apontadas por diversos autores, como Alencar e Fleith (2003a; 2003b), Castells (1999, 2003), Hill (2003), Ortiz (1994), Rifkin (2000).

Ao lado de tantas novidades e das transformações do mundo, cresceu o interesse por pesquisas no âmbito da criatividade, dando força ao novo, ao diferente, à busca de soluções para os inúmeros problemas e desafios e, segundo Alencar e Fleith (2003a), a necessidade de se pensar de forma criativa e inovadora tem levado vários sistemas educacionais de diferentes países a refletirem sobre o espaço que deve ser dado para o desenvolvimento das habilidades criativas no contexto educacional. Ressaltam ainda que os esforços nesse sentido têm sido precários, apesar de a criatividade ser um recurso natural do ser humano, não se constituindo um fenômeno exclusivamente cognitivo e nem exclusivo dessa ou daquela pessoa, porém seu desenvolvimento depende de vários fatores, tanto intrapessoais quanto do contexto sociocultural onde o indivíduo se insere e interage.

Também é preciso que os cursos formadores de professores, nas instituições de educação superior, conscientizem os futuros professores da importância da criatividade para si próprios e para os alunos que formarão, colocando a criatividade como instrumento do ensino-aprendizagem e como mola-mestra de respostas inovadoras e soluções desse novo contexto mundial. A ação educativa deve acompanhar a dinamicidade e o momento de transformação do mundo atual. Professores criativos passam para seus alunos esse espírito criativo; cabe-lhes estimular o potencial criador de seus alunos, contribuindo para que se constituam homens criativos no futuro.

Vários fatores contribuem para que os professores sejam criativos, destacando-se, entre eles, o fato de, em sua formação, terem sido estimulados a serem criativos e conscientizados da importância da criatividade na formação da pessoa bem como terem conhecido práticas pedagógicas que estimulassem a criatividade. Entretanto, segundo Libâneo (1998), as universidades formam mal os futuros professores sem as competências necessárias para enfrentar as mudanças que estão ocorrendo no mundo atual. Faltando em sua formação algumas competências e habilidades, os professores irão, conseqüentemente, formar mal seus alunos. Grande parte dos professores universitários somente se preocupa, no dia-a-dia, em reproduzir conhecimentos, não enfatizando o ensino reflexivo e crítico bem como não alertam os alunos "para o 'pulo do gato', que só os que se aventuraram na fantasia, na criação conseguem.” (Rosas, 1987, p. 123).

Muitos autores, segundo Alencar (200I), analisaram o ensino universitário, constatando ineficiência quanto à promoção da criatividade, o nãoencorajamento do pensamento criativo e independente, a ênfase na memorização e na reprodução de conhecimento. A mesma autora (1997), em pesquisa, a respeito da extensão em que a criatividade era estimulada no contexto universitário, observou que, segundo os estudantes de educação superior que participaram da mesma, os seus professores davam pouco incentivo a distintos aspectos da criatividade, eram pouco criativos e adotavam atitudes e metodologia de ensino também pouco criativas em sala de aula. Resultados similares a estes foram obtidos por Silva e Alencar (2003) com estudantes do Curso de Enfermagem.

Pode-se afirmar, de acordo com Morejón (1996), que o componente criativo é essencial à saúde mental e que à medida que os professores e alunos o tenham incorporado em suas próprias vidas, poderão desfrutar de experiências incríveis e se espantarem com o potencial desconhecido que possuíam e não conheciam.

Com base no exposto, a pesquisa objetivou analisar como a criatividade era percebida pelo professor do Curso de Letras, formador de professores da Língua Portuguesa, Literatura, entre outras disciplinas, nos seguintes aspectos: a importância atribuída à criatividade na formação do cidadão; as concepções de criatividade; a criatividade e o currículo do curso; o potencial criati- 
vo dos alunos; a formação do atual professor, se estes receberam noções sobre criatividade e se tiveram contatos com professores criativos; a percepção da sua própria criatividade; os procedimentos pedagógicos utilizados e que propiciavam o desenvolvimento da criatividade dos alunos e as barreiras ao desenvolvimento da criatividade em sala de aula.

\section{Método}

\section{Participantes}

Os participantes da pesquisa foram 20 professores do Curso de Letras, sendo 12 de duas instituições particulares e oito de uma instituição pública, todas situadas em uma cidade da região centro-oeste do Brasil. Dos entrevistados, oito (40\%) eram do sexo masculino e 12 (60\%) do sexo feminino $A$ idade dos participantes variou de 26 a 66 anos, com a média etária de 48 anos. A respeito da formação dos professores, constatou-se: um (5\%) com pós-doutorado; seis (30\%) com doutorado completo; três (15\%) com doutorado incompleto; oito (40\%) com mestrado completo; (5\%) com mestrado incompleto; um (5\%) com outra especialização. A carga média horária de trabalho era de 16 horas, assim distribuída: seis professores trabalhavam ate 10 horas, 10 professores trabalhavam de $1 \mathrm{I}$ a 20 horas, dois professores trabalhavam de 21 a 30 horas e dois professores trabalhavam de $3 \mathrm{I}$ a 40 horas. $\mathrm{O}$ tempo de magistério variou de um ano e meio a 38 anos, sendo que II (55\%) professores tinham entre 20 a 30 anos de magistério e nove (45\%) abaixo de 20 anos. Todos os professores afirmaram lecionar com grande satisfação e ministravam diferentes disciplinas no Curso de Letras.

\section{Instrumento}

O instrumento de pesquisa foi a entrevista, realizada de forma individual com professores do Curso de Letras e segundo roteiro, previamente preparado. Na sua parte inicial foram coletados dados pessoais do entrevistado (nome, gênero, idade, formação, disciplina(s) que lecionava, carga horária semanal, tempo de magistério e se tinham satisfação em lecionar). A seguir, foram feitas perguntas em que se buscou saber do entrevistado: o que ele achava da importân- cia da criatividade na formação do cidadão do mundo atual; qual o conceito que tinha a respeito de criatividade; se no currículo do curso de Letras da instituição onde lecionava havia uma disciplina específica para criatividade ou se ela era parte de alguma disciplina ou, ainda, se era apenas um procedimento pedagógico em sala de aula; se ele acreditava existir um potencial criativo em todas as pessoas e na possibilidade de desenvolvê-lo; se em sua formação, no curso superior, foi the dado conhecimentos sobre criatividade; se teve professores criativos em sua formação e o que deles se lembrava; se conhecia alguma técnica ou procedimento para desenvolver o potencial criativo das pessoas; se ele se considerava um professor criativo; que procedimentos pedagógicos/ técnicas/métodos de ensino utilizava e que, no seu entender, auxiliavam no desenvolvimento da criatividade de seus alunos; com quais barreiras se deparava em seu dia-a-dia de sala de aula e que percebia prejudicar o desenvolvimento do potencial criativo dos alunos. No encerramento da entrevista, permitiu-se ao entrevistado acrescentar o que quisesse e foram feitos os agradecimentos.

\section{Procedimento}

Primeiramente, houve um contato com a coordenação do Curso de Letras das duas instituições particulares para exposição dos objetivos da pesquisa e solicitar autorização para a realização das entrevistas. A partir de um primeiro professor entrevistado, outros foram indicados e assim, realizadas as demais entrevistas, em horários acertados com os professores. $\mathrm{Na}$ instituição pública, houve dificuldade de contato com a coordenação específica. Identificou-se, então, o horário de aula dos professores e a apresentação e solicitação de sua participação no estudo se deu diretamente com o professor, sendo a entrevista realizada em horário estipulado por ele. As entrevistas tiveram as seguintes etapas: apresentação da entrevistadora; explicação de seus objetivos e da confidencialidade; a realização propriamente dita; agradecimentos e despedida. As entrevistas, com uma duração média de 25 minutos, foram gravadas em áudio e transcritas verbatim.

Como etapa inicial da coleta de dados, procedeuse a um estudo piloto, com a participação de três 
professores, objetivando identificar possíveis falhas e o nível de clareza das perguntas incluídas no Roteiro de Entrevista. Não se constatou necessidade de modificações no roteiro previamente preparado e, por esta razão, os dados coletados nesse estudo foram aproveitados na análise.

\section{Análise dos dados}

Utilizou-se a análise de conteúdo, segundo orientações e prescrições preconizadas por diversos autores (Bardin, 2004; Bauer \& Gaskell, 2002; Franco, 2005; Richardson, 1999). As três fases da análise de conteúdo foram efetuadas: a da pré-análise do material, quando se sistematizou as idéias iniciais e se fez uma organização preliminar; a da exploração do material, quando a montagem de quadros resultou em respostas e operações de codificação, com a definição do tema como unidade de registro, enumeração e categorização, baseada nas questões formuladas; e a do tratamento dos resultados, a inferência e a interpretação. As freqüências e porcentagens de respostas em cada uma das categorias construídas foram calculadas.

\section{Resultados e Discussão}

\section{A importância da criatividade na formação do cidadão no mundo atual}

Dezenove (95\%) professores concordaram com a importância da criatividade no mundo de hoje; apenas um professor deu uma resposta evasiva. Os motivos explicitados relacionavam-se à profissão, à vida pessoal, ao mundo em geral e ao modismo, conforme Tabela I.

Algumas citações dos professores a respeito:

Hoje eu acredito que a criatividade, ela faça a diferença entre dois profissionais [...] Para a escolha de

Tabela I. Motivos apontados pelos professores para justificar a importância da criatividade na formação do cidadão no mundo atual

\begin{tabular}{|c|c|c|c|}
\hline \multicolumn{2}{|l|}{ Motivos } & \multirow{2}{*}{$\mathrm{f}$} & \multirow{2}{*}{$\%$} \\
\hline Relacionados & Explicitados & & \\
\hline Profissão & $\begin{array}{l}\text { - Faz a diferença entre dois profissionais } \\
\text { - Serve para a escolha de profissionais } \\
\text { - Serve para solução de problemas na sala de aula } \\
\text { - Torna prazeroso o exercício da profissão } \\
\text { - É meio de sobrevivência } \\
\text { - Permite inovações no método, no procedimento no } \\
\text { relacionamento } \\
\text { - Serve para fazer um trabalho diferenciado }\end{array}$ & 12 & 46,15 \\
\hline $\begin{array}{l}\text { Formação da } \\
\text { Pessoa }\end{array}$ & $\begin{array}{l}\text { - Serve para o desenvolvimento pessoal e intelectual } \\
\text { - Serve como diferencial na busca de emprego } \\
\text { - Serve para encontrar soluções de problemas pessoais }\end{array}$ & 8 & 30,77 \\
\hline $\begin{array}{l}\text { Mundo em } \\
\text { Geral }\end{array}$ & $\begin{array}{l}\text { - Inovação } \\
\text { - Desenvolvimento } \\
\text { - Solução de problemas do mundo }\end{array}$ & 5 & 19,23 \\
\hline Modismo & - Mais um tema na moda pedagógica & 1 & 3,85 \\
\hline TOTAL & & 26 & 100,00 \\
\hline
\end{tabular}

Nota: as porcentagens foram calculadas a partir do total de motivos explicitados e não a partir do número de professores entrevistados. 
um profissional, a criatividade influenciará nessa escolha, nessa seleção [...] o conhecimento pode ser equivalente e a diferença ser a criatividade. (PI)'.

[...] a criatividade, sob meu ponto de vista, é uma questão de sobrevivência no mundo do trabalho. (P5).

A importância da criatividade nos tempos atuais, discutidos por vários pesquisadores (Alencar \& Fleith, 2003a; Castells, 2003; Ortiz, 1994, entre outros), foi também ratificada pelos participantes da pesquisa, que enfatizaram sua relevância, sobretudo no âmbito profissional. A criatividade foi considerada questão de sobrevivência no trabalho. A importância da criatividade no trabalho foi também apontada pela pesquisa de Melo (200I, p. 8I) que afirmou ser a criatividade "um trunfo para os professores de Educação alcançar os objetivos traçados para suas aulas, ultrapassando os obstáculos encontrados". Foi realçada a validade de sua utilização em sala de aula pelo professor, seja para deixar mais atrativa a forma de ministrar determinado conteúdo e motivar os alunos, seja para melhorar a relação entre professor e aluno, por meio de determinados procedimentos pedagógicos por eles adotados.

\section{Concepções de criatividade}

Várias idéias foram associadas ao conceito de criatividade, agrupadas em quatro categorias (Tabela 2): criatividade como geradora do novo; criatividade como transformadora de algo; criatividade como atributo pessoal e criatividade como geradora de soluções.

Isso é demonstrado por algumas afirmativas dos professores:

É a capacidade... é a inventiva... é apresentar algo novo, apresentar algo inédito, alguma coisa que poucos ou ninguém pensou antes. $(\mathrm{FI} 9)^{2}$.

Então, assim eu entendo por criatividade uma que- bra de padrão, uma quebra de paradigma, seja no individual, seja no coletivo. (F20).

que entendo por criatividade é: inovar, ser crítico, é questionar, é não seguir a norma, embora tendo por base a norma, para ser criativo. (P3).

Criatividade é fazer releituras, fazer reelaboração de idéias, é reorganização, é reconstrução de idéias, mesmo que a idéia seja antiquada, mesmo que a idéia seja tradicional, ela pode ser revista, refeita, relida e apresentar aquela mesma idéia de uma forma mais moderna [...] (PI).

[...] é exatamente essa habilidade, esse traquejo, de conseguir às vezes do pouco o muito, essa coisa de você transformar o que é difícil numa coisa fácil, para o aluno entender [...] (P2).

Diversos pesquisadores da criatividade (Alencar \& Fleith, 2003a; Amabile, 1999; Feldman, Csikszentmihalyi \& Gardner, 1994; Martínez, 1997; Niu \& Sternberg, 2002; Prado-Diez, 1999; Wechsler, 2002, entre outros) evidenciaram que a criatividade está em todos os lugares, todas as pessoas a intuem, a percebem, mas uma definição precisa, única, concreta é difícil de ser estabelecida e que ao seu conceito ligam-se expressões como: novo, original, útil, valor social num momento histórico, diferente, desenvolvimento, melhoria, solução de problemas. Esses aspectos foram apontados pelos entrevistados que demonstraram saber o que é criatividade, no seu foro íntimo, mas tiveram dificuldade em defini-la, o que pode ser percebido pelas muitas reticências, silêncio para pensar, outras perguntas, exclamações e respostas indiretas, exemplificações de procedimentos que adotavam e que proporcionavam momentos criativos.

\section{Criatividade no currículo do Curso de Letras}

Uma análise das respostas (Tabela 3) indicou quatro enfoques: não havia uma disciplina específica so-

\footnotetext{
PI - o professor entrevistado de instituição de educação superior particular foi codificado com a letra $\mathrm{P}$ e o número à direita representa a ordem em que ocorreu a entrevista.

${ }^{2} \mathrm{FI} 9$ - o professor entrevistado de instituição de educação superior pública foi codificado com a letra $\mathrm{F}$ e o número à direita representa em que ordem ocorreu a entrevista.
} 
Tabela 2. Concepções de criatividade explicitadas pelos participantes do estudo

\begin{tabular}{|c|c|c|c|}
\hline \multicolumn{2}{|c|}{ Concepções Explicitadas } & $\mathrm{f}$ & $\%$ \\
\hline $\begin{array}{l}\text { Criatividade } \\
\text { como geradora } \\
\text { do novo }\end{array}$ & $\begin{array}{l}\text { - É inovação, inventiva } \\
\text { - Serve para gerar algo novo, diferenciado } \\
\text { - Serve para gerar novos relacionamentos } \\
\text { - É uma quebra de padrões, normas,paradigmas } \\
\text { - Serve para sair da mesmice }\end{array}$ & 9 & 36,00 \\
\hline $\begin{array}{l}\text { Criatividade } \\
\text { como } \\
\text { transformadora }\end{array}$ & $\begin{array}{l}\text { - Faz releituras } \\
\text { - Reelabora, reorganiza, reconstrói idéias } \\
\text { - Interliga e interrelaciona conhecimentos } \\
\text { - Reorganiza valores } \\
\text { - Transforma o difícil em fácil } \\
\text { - Melhora algo }\end{array}$ & 7 & 28,00 \\
\hline $\begin{array}{l}\text { Criatividade } \\
\text { como atributo } \\
\text { pessoal }\end{array}$ & $\begin{array}{l}\text { - É uma habilidade, traquejo } \\
\text { - Torna a pessoa crítica e questionadora } \\
\text { - É a capacidade de pensar, imaginar e inventar } \\
\text { - Gera prazer, satisfação em fazer } \\
\text { - Dá identidade ao ser }\end{array}$ & 7 & 28,00 \\
\hline $\begin{array}{l}\text { Criatividade } \\
\text { como geradora } \\
\text { de soluções }\end{array}$ & - Auxilia na busca de soluções de problemas & 2 & 8,00 \\
\hline TOTAL & & 25 & $100,00 \%$ \\
\hline
\end{tabular}

bre criatividade no currículo do Curso de Letras; a criatividade como prática pedagógica; a criatividade como parte de outra disciplina; e a necessidade de uma disciplina específica sobre criatividade no curso de licenciatura.

Embora os estudiosos do assunto profissão professor, como Freire e Shor (1996), Porto (2002), Tardif (2003), Tibeau (2002), Zabalza (1998), entre outros, enfatizem que é necessário que a criatividade seja enfocada nos cursos de formação, percebeu-se que o currículo do Curso de Letras não trata do assunto. $\mathrm{Na}$ melhor das hipóteses, é incluída nos procedimentos pedagógicos dos pro- fessores, sendo uma prática individual e intuitiva, mas não de todos os professores ou faz parte de disciplinas práticas, como Didática, mas também não como um conteúdo explícito.

\section{Potencial criativo e suas possibilidades de desenvolvimento}

Uma análise das respostas à questão sobre o que o professor entrevistado pensava sobre o potencial criativo das pessoas e a possibilidade de desenvolvêlo indicou que, para 18 (90\%) professores, o potencial criativo está presente em todas as pessoas, enfatizando terem algumas esse potencial desenvol- 
Tabela 3. Criatividade no currículo do Curso de Letras

\begin{tabular}{|c|c|c|c|}
\hline \multicolumn{2}{|c|}{ Enfoques Explicitados } & \multirow{2}{*}{$\begin{array}{c}\mathrm{f} \\
\mathrm{1}\end{array}$} & \multirow{2}{*}{$\begin{array}{c}\% \\
35,29\end{array}$} \\
\hline $\begin{array}{l}\text { Inexistência da } \\
\text { disciplina } \\
\text { criatividade }\end{array}$ & - Não há no currículo & & \\
\hline $\begin{array}{l}\text { Criatividade como } \\
\text { procedimento } \\
\text { pedagógico }\end{array}$ & $\begin{array}{l}\text { - Depende da disciplina ministrada } \\
\text { - Fica a critério do professor }\end{array}$ & 12 & 35,29 \\
\hline $\begin{array}{l}\text { Criatividade como } \\
\text { integrante de outra } \\
\text { disciplina }\end{array}$ & $\begin{array}{l}\text { - Disciplinas de ordem prática (Estágio, } \\
\text { Didática e outras) }\end{array}$ & 7 & 20,60 \\
\hline $\begin{array}{l}\text { Criatividade como } \\
\text { disciplina distinta }\end{array}$ & - Seria interessante, mas não imagina como & 3 & 8,82 \\
\hline Total & & 34 & 100,00 \\
\hline
\end{tabular}

vido, ao passo que outras o apresentam em estado bruto, havendo necessidade de um esforço para aflorá-lo. Mas mesmo assim, acreditavam na possibilidade de desenvolvê-lo em todas as pessoas, sendo a ação e o método de ensinar do professor fundamentais. Somente dois (10\%) professores consideraram que algumas pessoas não tinham potencial criativo.

Seguem algumas respostas:

Eu acredito, isso é cientificamente já comprovado, Gardner já provou isso. (P2).

Sim, sem dúvida. Eu acho que todo o mundo tem a capacidade de estar disponibilizando o desenvolvimento dessa habilidade; sim, acho até que é uma competência; o que precisa é de um trabalho que estimule esse potencial criativo. (P6).

Com certeza, com certeza, eu acho que as convenções, as normas, as leis, os sistemas inibem um pouco $[\ldots](\mathrm{FI} 3)$.

A grande maioria das respostas está em consonância com o que os estudiosos da criatividade, como Alencar (2000a, 2000b, 200 I, 2002), Alencar e Fleith (2003a), Fleith (200I), Feldman e cols. (1994), Freire e Shor (1996), Martínez (1997),
Morejón (1996), Sternberg e Lubart (1996), Tardif (2003), Vallejo (2003), Vygotsky (1930/1987), Wechsler (200I, 2002), Zabalza (1998), entre outros, salientaram: todas as pessoas têm um potencial criativo e é preponderante a ação do professor no desenvolvimento desse potencial; muitas pessoas o têm em estado latente, algumas o têm desenvolvido naturalmente e outras o têm em desenvolvimento, de acordo com os estímulos que recebem pelos diversos ambientes por onde passa. A maioria acredita no potencial existente nas pessoas, havendo muita ênfase, entretanto, em se afirmar que é necessário um esforço para desenvolver esse potencial, até mesmo um "empurrãozinho, um pontapé inicial".

\section{Criatividade na formação dos professores entrevistados}

Uma análise das respostas à questão (Tabela 4) indicou que a grande maioria delas demonstrou que os professores não receberam informações sobre criatividade em sua formação, tendo mesmo alguns ressaltados que, ao contrário, haviam sido castrados na sua criatividade em potencial e que a formação foi mais conteudista. Alguns tiveram noções em disciplina prática ou pela prática pedagógica de certos professores. 
Tabela 4. Criatividade na formação dos professores entrevistados

\begin{tabular}{llcc}
\hline \multicolumn{2}{l}{ Categorias de Respostas } & $\mathrm{f}$ & $\%$ \\
\hline $\begin{array}{l}\text { Nenhuma } \\
\text { informação } \\
\text { sobre } \\
\text { criatividade na } \\
\text { formação }\end{array}$ & - Formação conteudista & 15 & 68,18 \\
\hline $\begin{array}{l}\text { Alguma } \\
\text { informação }\end{array}$ & $\begin{array}{l}\text { - Enfoque de criatividade em certas disciplinas (Didática e castradora } \\
\text { nobre } \\
\text { criatividade }\end{array}$ & $\begin{array}{l}\text { - Ação do professor à criatividade, mas sem técnicas } \\
\text { específicas }\end{array}$ & 2 \\
$\begin{array}{l}\text { Iniciativa } \\
\text { pessoal }\end{array}$ & - Família & 9,09 \\
\hline $\begin{array}{l}\text { Informação em } \\
\text { disciplina } \\
\text { específica de } \\
\text { criatividade }\end{array}$ & - Busca pessoal & 4 & 18,19 \\
\hline TOTAL & No curso de mestrado & & \\
\hline
\end{tabular}

Nota: as porcentagens foram calculadas com base no total de respostas referentes às distintas categorias e não a partir do número de professores.

Algumas respostas ilustrativas:

[...] tive uma educação absolutamente tradicional, conteudista [...] (P2).

Não, pelo contrário, o que houve em toda minha formação foi podar toda a criatividade, sempre. (FI4).

Não... uma disciplina específica também, mas justamente na prática de ensino, nós trabalhamos muito isso: criatividade e motivação, criatividade e motivação em sala de aula, no Curso de Letras [...] (PI5).

Formalmente não, mas assim, acho que tem mais a ver com minha formação de família [...] (FI8).

Nada, só no Mestrado. (P3).

Com relação à formação dos professores entrevistados, observou-se que está em conformidade com o estabelecido legalmente, porém, a criatividade foi uma das lacunas deixada na formação do atual professor do Curso de Letras, que foi mais teórica e continua sendo. Todos sabem que a criatividade é importante, mas não sabem como desenvolvê-la eficazmente em seus alunos.

\section{Professores criativos na formação dos participantes}

Constatou-se que $10(50 \%)$ professores responderam afirmativamente, informando que se lembravam desses professores com enorme satisfação, o que transpareceu, inclusive, no semblante que expressaram, com um sorriso nos lábios. Um dos professores realçou as instituições onde estudou, as quais estimulavam os alunos a serem criativos por meio de práticas pedagógicas incentivadoras. Entretanto, observou-se que foram poucos os professores lembrados. Para nove (45\%) participantes do estudo, a lembrança que tinham era somente de professores castradores da criatividade. Entre os professores entrevistados, apenas um não respondeu a essa pergunta, afirmando que criatividade era algo pessoal e não estava nos focos das suas preocupações.

A seguir, algumas respostas dos professores entrevistados:

Tive, tive professores criativos, tive nessa época, ah, eu tive um professor que fazia a gente desenhar, representar [...] (P2). 
Tive, tive. Assim, a grande sabedoria dessas pessoas de não falar só de um assunto, mas estar sempre relacionando vários assuntos e voltando àquele assunto. (P4).

Criativos? Tive... uma professora de Didática que é assim de quem mais eu me lembro quando estou preparando as minhas aulas, é dela que me lembro. (P7).

Professores criativos serão lembrados por seus alunos, professores que apresentam inovações em sala de aula, que dão aula com prazer. Esse fato foi comprovado pelos professores que se recordaram dos poucos professores criativos que tiveram em sua formação, cuja lembrança veio acompanhada de satisfação demonstrada no semblante do professor. Professores castradores marcam negativamente por toda a vida e a maioria os tiveram em sua formação.

\section{Conhecimento sobre técnica ou procedi- mento específico para desenvolver o poten- cial criativo}

Dos 20 professores entrevistados, $18(90 \%)$ informaram desconhecer a técnica ou o procedimento específico para desenvolver o potencial criativo, embora tenham aproveitado para apontar procedimentos utilizados durante as aulas e que consideravam estimuladores da criatividade dos alunos como, por exemplo: divisão dos alunos por habilidades e capacidades na hora de fazer um trabalho, utilização de muita leitura, experiências em sala de aula, diálogo, questionamentos, trabalhos em grupo, elaboração de jornal e poesias. Apenas um professor informou conhecer algumas técnicas para desenvolver o potencial criativo, pois cursou uma disciplina sobre criatividade durante o Mestrado, mas não as utilizava. Um professor não se interessava por criatividade em suas aulas.

Algumas citações ilustrativas:

Técnica que eu tenha feito, por exemplo, como disciplina, ou que tenha aprendido com professores, não [...]. Aprendi com os próprios alunos, com as necessidades deles [...] Por exemplo, então primei- ro minhas aulas são teóricas [...] assim é que funciona na academia; mas, em outro momento, eles utilizam este conhecimento para apresentações de trabalho, não em seminários, mas em dupla, ou em trio, que seria uma simulação de sala de aula $[. .].(\mathrm{PI})$.

Eu conheço as técnicas que eu uso em sala de aula, né, eu normalmente divido por habilidades, por competências, os alunos é que estabelecem naquilo que eles se encontram, naquilo que eles melhor têm e trabalham em grupo de acordo com as habilidades que eles têm. (P2).

Não, eu vou assumir para você, é uma coisa mais intuitiva que eu tenho, mas nenhuma técnica específica assim... ler um livro, ou alguém ter me indicado, não, nem curso. (P5).

Quase a totalidade da amostra não conhece técnica ou prática pedagógica que possibilite o desenvolvimento do potencial criativo das pessoas, exercícios específicos que possibilitem a produção de idéias e soluções criativas como os citados por Alencar (2000), Alencar e Fleith (2003a), Buzan (200I), De La Torre (2003), Fleith (200I), entre outros. Desconhece também livros a respeito de criatividade. $\mathrm{O}$ que poderia suprir essa carência seria um programa de atualização, que também é precário nas instituições pesquisadas. Constatou-se grande desinformação em relação à criatividade, leituras correlatas, técnicas e procedimentos de desenvolvimento do potencial criativo e cursos sobre o tema. A pesquisa realizada por Alencar e Fleith (2004), com uma amostra de professores e alunos da educação superior, a respeito da extensão em que a criatividade era incentivada por aqueles professores em sala de aula, explicitou, entre seus resultados, a necessidade dos professores meIhor se equiparem e se prepararem para terem condições de incentivar a criatividade de seus alunos.

\section{Percepção dos entrevistados quanto à sua criatividade}

Entre os 20 professores entrevistados, 14 (70\%) se consideravam criativos, apresentando como justificativas estarem sempre buscando algo diferenciado para dinamizar sua aula, atrair a atenção dos alunos e 
motivá-los à participação. Cinco (25\%) professores responderam que às vezes são criativos e apenas um professor não se considerava criativo.

Algumas respostas obtidas são apresentadas a seguir:

Me considero, porque consigo prender a atenção de meus alunos, eles gostam da aula, quando eu falto eles sentem falta de mim [...] (P8).

Bastante, bastante, todo semestre eu invento uma coisa nova para os cursos, para as disciplinas [...] eu não fico repetindo, eu mudo o texto, mudo a estratégia, mudo a maneira de lidar com as pessoas na sala de aula $[\ldots]$ (F20).

Olha, se eu me considero uma professora criativa? Eu poderia ser bem mais, se me permitissem, mas é que na sala de aula eu tento ser. (P3).
Procedimentos pedagógicos adotados no dia-a-dia em sala de aula e que, segundo os professores, contribuem para o desenvolvimento da criatividade dos alunos

Uma análise das respostas (Tabela 5) indicou que, com exceção de um professor que afirmou que a criatividade não fazia parte de suas preocupações pedagógicas e sim o conteúdo de sua disciplina, os demais professores citaram procedimentos pedagógicos que utilizavam e que propiciavam o desenvolvimento da criatividade em suas aulas.

llustram as respostas:

Procuro valorizar, ao invés de contar, exclusivamente, com aquilo, com as respostas de conteúdo, procuro onde foi que ele tentou... o que ele acrescentou com aquelas respostas ou aquele trabalho que ele fez, tem também um valor, ao lado do conteúdo. (P9).

Tabela 5. Procedimentos pedagógicos que contribuem para o desenvolvimento da criatividade do aluno

\begin{tabular}{|c|c|c|c|}
\hline Procedimentos 1 & dagógicos & $\mathrm{f}$ & $\%$ \\
\hline \multirow{8}{*}{$\begin{array}{l}\text { Procedimentos } \\
\text { gerais do } \\
\text { professor }\end{array}$} & $\begin{array}{l}\text { - Envolvimento do aluno nas atividades, levando- } \\
\text { o à reflexão, à criação, ao questionamento }\end{array}$ & \multirow{8}{*}{13} & \multirow{8}{*}{59,10} \\
\hline & - Valorização do esforço do aluno & & \\
\hline & $\begin{array}{l}\text { - Adoção de postura dialógica, provocativa de } \\
\text { desafios, questionadora }\end{array}$ & & \\
\hline & $\begin{array}{l}\text { - Consecução de mudanças simples, como o } \\
\text { layout da sala }\end{array}$ & & \\
\hline & - Uso da intuição e sensibilidade & & \\
\hline & - Atenção às necessidades dos alunos & & \\
\hline & - Muita leitura & & \\
\hline & $\begin{array}{l}\text { - Pontuação maior para a criatividade nos } \\
\text { trabalhos }\end{array}$ & & \\
\hline \multirow{4}{*}{$\begin{array}{l}\text { Procedimentos } \\
\text { específicos } \\
\text { para ministrar } \\
\text { aula }\end{array}$} & $\begin{array}{l}\text { - Divisão dos alunos por habilidades e } \\
\text { competências }\end{array}$ & \multirow{4}{*}{9} & \multirow{4}{*}{40,90} \\
\hline & $\begin{array}{l}\text { - Produção diversificada (trabalhos individuais e } \\
\text { grupais, elaboração de jornais, diários, poesias) }\end{array}$ & & \\
\hline & $\begin{array}{l}\text { - Utilização de diálogo, questionamentos, } \\
\text { discussões, seminários, estudo de caso }\end{array}$ & & \\
\hline & $\begin{array}{l}\text { - Montagem de grupos diferenciados (musical, } \\
\text { teatral) }\end{array}$ & & \\
\hline \multicolumn{2}{|l|}{ Total } & 22 & 100,00 \\
\hline
\end{tabular}

Nota: as porcentagens foram calculadas a partir do total do número de procedimentos pedagógicos adotados pelos professores e não sobre o número de professores entrevistados. 
[...]porque eles são danados para esse tipo de coisa, eles são muito criativos nesse sentido e eles se organizam de acordo com as habilidades que eles têm." (P2)

[...]aluno que reflete e que produz está sendo criativo[...] (F20).

Os procedimentos pedagógicos utilizados e que os professores acreditavam desenvolver a criatividade não eram intencionalmente adotados, mas usados de forma intuitiva e para estimular a atenção dos alunos e motivá-los à disciplina. Mas mesmo assim, houve mostra de muitas atividades condutoras à criatividade, como incentivo a debates, elaboração de trabalhos criativos (jornal, diário, poesias, teatro e outros). Ressalta-se que Alencar (2000b) constatou, em pesquisa com estudantes de pós-graduação, que as técnicas instrucionais são forte referência para o desenvolvimento da criatividade. Fleith (2000) também investigou a percepção de professores e estudantes do ensino fundamental sobre criatividade no ambiente escolar e entre os vários resultados, estava o da percepção de que o ambiente escolar influenciava no desenvolvimento da criatividade dos estudantes, sendo identificados três pontos principais: atitudes, estratégias e atividades.

\section{Barreiras ao desenvolvimento da criatividade}

O último tópico focalizado nas entrevistas foram as barreiras percebidas pelo professor ao desenvolvimento da criatividade dos alunos (Tabela 6). Foram apontadas barreiras referentes ao aluno, à instituição, aos colegas de profissão, inerentes à formação do professor e relacionadas ao modo de ser do professor em sala de aula.

São exemplos de respostas a essa questão:

Se você criar métodos diferentes em sala de aula, questão de discussão, eles vão dizer que nós não estamos dando aula: ué, cadê a aula? (P5).

E algumas vezes também a instituição não oferece grandes possibilidades - você tem o que ser feito naquela grade, dentro daquele momento, e se você foge demais [...] (PI7).
Os colegas detestam, às vezes, porque... se ela está fazendo assim, eu vou ter que fazer também [...] (FI6).

[...] falta de atualização dos professores, né... que faz com que não desenvolva o potencial dos alunos, fica preso à mesma coisa, acha que está sempre com a mesma turma, a falta de escuta também por parte dos professores - a gente escuta pouco os alunos. (P3).

Alunos, ah, muitos não querem, por exemplo, os que não querem lecionar são mais inibidos, não querem esse tipo de aula prática, né? Outros acham, se esquecem que estão fazendo licenciatura e acham que o nível da aula do $3^{\circ}$ grau deve ser absolutamente o mais próximo do mestrado. (PI).

Notou-se que, para os entrevistados, o maior número de barreiras estava relacionado aos alunos. A timidez e as personalidades diferentes não os deixavam se expressar de forma criativa. O cansaço, sobretudo nos alunos das instituições particulares, cujos cursos eram noturnos e os alunos trabalhavam, de modo geral, durante o dia, foi considerada barreira para o professor tentar fazer algo diferente. Por outro lado, para os professores, os alunos demonstravam uma certa avidez por teoria, pois muitos pensavam que o professor que não agia dentro dos "padrões normais de despejar teoria", era um professor que queria "enrolar o tempo". Houve quem expressasse sua admiração pelos jovens que chegavam à educação superior absolutamente contra o novo, porque isso implicava esforçar-se mais mentalmente e percebia que eles queriam continuar a fazer o que todo o mundo fazia, porque o novo dava mais trabalho. Foi também citada a constatação de que os alunos do primeiro semestre eram mais resistentes dos que os dos semestres seguintes, porque vinham do ensino médio, voltado para o vestibular, cuja preocupação era fazer o maior número de ingressantes nos cursos superiores. Outra barreira indicada foi a pouca predisposição dos alunos à leitura, o que impedia a realização de trabalhos mais criativos. Foram também realçados fatores ligados à instituição, sobretudo rigidez no cumprimento da grade curricular e falta de material, principalmente nas ins- 
Tabela 6. Barreiras ao desenvolvimento da criatividade do aluno

\begin{tabular}{|c|c|c|c|}
\hline $\begin{array}{l}\text { Barreiras } \\
\text { relacionadas }\end{array}$ & Barreiras apontadas & $\mathrm{f}$ & $\%$ \\
\hline Aluno & $\begin{array}{l}\text { - Timidez } \\
\text { - Cansaço } \\
\text { - Avidez por teoria } \\
\text { - Personalidades diferentes } \\
\text { - Pouca leitura } \\
\text { - Desmotivação para a disciplina } \\
\text { - Resistência à mudança e ao novo } \\
\text { - Despreparo }\end{array}$ & 12 & 40,00 \\
\hline Instituição & $\begin{array}{l}\text { - Horário } \\
\text { - Grade curricular } \\
\text { - Academicismo } \\
\text { - Carência de espaço para laboratórios, teatro } \\
\text { - Carência de materiais } \\
\text { - Carência financeira }\end{array}$ & 8 & 26,67 \\
\hline $\begin{array}{l}\text { Colegas de } \\
\text { profissão }\end{array}$ & $\begin{array}{l}\text { - Resistência à criatividade } \\
\text { - Resistência em fazer diferente o que vem fazendo }\end{array}$ & 4 & 13,33 \\
\hline $\begin{array}{l}\text { Formação do } \\
\text { professor }\end{array}$ & $\begin{array}{l}\text { - Formação tradicionalista } \\
\text { - Falta de atualização } \\
\text { - Não saber escutar os alunos } \\
\text { - Desconhecimento do assunto }\end{array}$ & 3 & 10,00 \\
\hline $\begin{array}{l}\text { Professor em } \\
\text { sala de aula }\end{array}$ & $\begin{array}{l}\text { - Conteúdo teórico } \\
\text { - Academicismo }\end{array}$ & 3 & 10,00 \\
\hline Total & & 30 & 100,00 \\
\hline
\end{tabular}

Nota: as porcentagens foram calculadas a partir do total de barreiras apontadas pelos professores e não a partir do número de professores.

tituições particulares. Foi também apontada como barreira a resistência dos colegas de profissão; vários deixaram de adotar procedimentos mais criativos em suas aulas por causa de colegas que se sentiam inferiorizados, mas não queriam ter mais trabalho. As barreiras relacionadas ao professor em sua formação ou em sua atuação em sala de aula se referiam, especialmente, à formação tradicionalista com ênfase no conteúdo, ao desconhecimento do assunto criatividade, à falta de atualização e ao ensino teórico, que tem sido transmitido nos cursos de formação de professor, inclusive no Curso de Letras.
Ratificando as palavras de Amabile (1999, p. I I0) de que "sufocar a criatividade é fácil, difícil é estimulála", a pesquisa demonstrou existirem, nos Cursos de Letras, barreiras ao desenvolvimento da criatividade, que constam das pesquisas de estudiosos do assunto (Alencar \& Fleith, 2003a; Morejón, 1996; Perrenoud, 1999; Uano, 2002, entre outros). Resultados semeIhantes foram alcançados em pesquisa com professores de História do ensino fundamental por Mariani e Alencar (2005) que constataram que, segundo os docentes, $\mathrm{o}$ aluno e a estrutura escolar eram fortes inibidores da criatividade. 


\section{Conclusões}

Esta pesquisa permitiu analisar o Curso de Letras sob outro olhar: o olhar da criatividade. O Curso de Letras dá margem ao uso intensivo da criatividade por sua característica de lidar com a fala, a escrita, a imaginação, a descrição, a leitura e a interpretação. Segundo Braga e Alencar (2003, p. 104), embora existam muitos estudos na área de Literatura e diversas teorias sobre um processo de ensino-aprendizagem, abordando mais significativamente os conteúdos, "o ensino da Literatura ainda não alcançou o seu amadurecimento", pois ainda deixa muito a desejar a respeito da formação do pensamento crítico, por continuar sendo muito conteudista e a Literatura estudada como algo distante da realidade prática da vida. Para esses autores, os professores, na visão dos alunos, precisam repensar a prática pedagógica para conquistar uma verdadeira educação e utilizar as disciplinas, como a Literatura, para auxiliar na formação do cidadão de amanhã.

Como assinalam Alencar e Fleith (2003a), embora haja reconhecimento da importância da criatividade e de se estimular as habilidades criativas nos alunos, pouco tem sido feito, intencionalmente, para favorecer seu desenvolvimento, o que ficou também demonstrado pela presente pesquisa. Isso se deve à desinformação dos professores quanto às estratégias e atividades promotoras do potencial criativo, às insipientes iniciativas das instituições de ensino para inclusão de uma disciplina ou conteúdos sobre criatividade e aos parcos programas de atualização dos atuais professores.

Ratificando as palavras de Sousa (2006, p. I): "até que ponto a formação de professores em criatividade poderá ditar uma melhoria efetiva na abordagem que estes fazem em relação ao ato pedagógico e a toda a envolvente escolar?" O autor tenta responder, afirmando que "não se tratará apenas de mais uma matéria, uma curiosidade, uma 'gracinha' da psicologia", mas sim algo que ditará uma melhoria efetiva do ato pedagógico e de todo o processo educativo. Como afirma Sousa (2006, p. 3), o ensino tradicional precisa se alterar para ser um ensino criativo, que os alunos busquem a escola não só para adquirir conhecimentos já existentes, mas para adquirir perícias que
Ihes permitam lidar com desafios e acontecimentos imprevistos e que a educação não seja vista como suplementar e preparatória para a vida, mas como um componente da vida e do progresso do mundo.

\section{Referências}

Alencar, E. M. L. S. (1997). O estímulo à criatividade no contexto universitário. Psicologia Escolar e Educacional, I, 29-37.

Alencar, E. M. L. S. (2000a). O perfil do professor facilitador e do professor inibidor da criatividade segundo estudantes de pós-graduação. Boletim da Academia Paulista de Psicologia, 19 , 84-94.

Alencar, E. M. L. S. (2000b). O processo da criatividade. São Paulo: Makron Books.

Alencar, E. M. L. S. (200I). Criatividade em cursos universitários: o papel do professor. I Seminário interno sobre educação superior da Universidade Católica de Brasília. Brasília: Universa.

Alencar, E. M. L. S. (2002). O contexto educacional e sua influência na criatividade. Linhas Críticas, 8, I65-178.

Alencar, E. M. L. S., \& Fleith, D. S. (2003a). Criatividade múltiplas perspectivas. Brasília, DF: Editora da Universidade de Brasília.

Alencar, E. M. L. S., \& Fleith, D. S. (2003b). Contribuições teóricas recentes ao estudo da criatividade. Psicologia: Teoria e Pesquisa, 19, 1-8.

Alencar, E. M. L. S., \& Fleith, D. S. (2004). Creativity in university courses: Perceptions of professors and students. Gifted and Talent International, 19, 24-28.

Amabile, T. M. (1999). Como não matar a criatividade. HSM Management, 3, II0-1 I7.

Bardin, L. (2004). Análise de conteúdo. Lisboa: Edições 70.

Bauer, M. W., \& Gaskell, G. (2002). Pesquisa qualitativa com texto, imagem e som: um manual prático. Petrópolis: Vozes.

Braga, A. E., \& Alencar, E. M. L. S. (2003). Avaliação do ensino de Literatura por professores e estudantes do ensino médio. Educação Brasileira, 25, 89-107.

Buzan, T. (200I). O poder da inteligência criativa. São Paulo: Cultrix.

Castells, M. (1999). A era da informação: economia, sociedade e culturas. Fim de milênio. (vol. III). Rio de Janeiro: Paz e Terra. 
Castells, M. (2003). A era da informação: economia, sociedade e culturas. (vol. I). Rio de Janeiro: Paz e Terra.

De La Torre, S. (2003). Dialogando com a criatividade. São Paulo: Madras.

Feldman, D. H., Csikszentmihalyi, M., \& Gardner, H. (1994). Changing the world. A framework for the study of creativity. Westport: Praeger Publishers.

Fleith, D. S. (2000). Teacher and student perceptions of creativity in the classroom environment. Roeper Review, 22, |48-153.

Fleith, D. S. (200I). Criatividade: novos conceitos e idéias, aplicabilidade à educação. Cadernos de Educação Especial, I7, 55-6I.

Franco, M. L. P. B. (2005). Análise do conteúdo. Brasília: LiberLivro.

Freire, P., \& Shor, I. (1996). Medo e ousadia - o cotidiano do professor. São Paulo: Paz e Terra.

Hill, D. (2003). O neoliberalismo global, a resistência e a deformação da educação. Currículo sem Fronteiras, 3, 2459. [On-line]. Disponível em: http:// curriculosemfronteiras.org/artigos. Recuperado: 3 I/08/04.

Libâneo, J. C. (1998). Adeus professor, adeus professora?: novas exigências profissionais e profissão docente. São Paulo: Cortez.

Mariani, M. F., \& Alencar, E. M. L. S. (2005). Criatividade no trabalho docente segundo professores de História. Psicologia Escolar e Educacional, 9, 27-35.

Martínez, A. M. (1997). Criatividade, personalidade e educação. São Paulo: Papirus.

Melo, A. C. R. (200I). Educação física adaptada e criatividade. Dissertação de Mestrado, Universidade Católica de Brasília, Brasília-DF.

Morejón, J. B. (1996). Psicología y creatividad: apuntes y reflexiones. Guadalajara: Editorial de la Universidad de Guadalajara.

Niu, W., \& Sternberg, R. (2002). Contemporary studies on the concept of creativity: the east and the west. The Journal of Creative Behavior, 36(4), 269-284.

Ortiz, R. (1994). Mundialização e cultura. São Paulo: Cultrix.

Perrenoud, P. (1999). Os dez não ditos ou a face escondida da profissão docente. Faculdade de Psicologia e Ciências da Educação, Universidade de Genebra, Genebra. [On-line]. Dis-

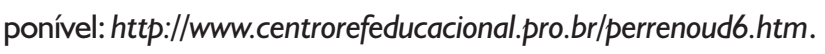
Recuperado: 0I nov. 2005.
Porto, G. (2002). A propósito da formação de professores. Revista de Pedagogia, 6, ago./dez. [On-line]. Disponível: http:/ /www.fe.unb.br/revistadepedagogia/numeros/06/ editorial.htm. Recuperado: 29 jun. 2005.

Prado-Diez, D. (1999). Analogía inusual. Colección Monografías Master de Creatividad. Servicio de Publicacións e Intercambio Científico. Santiago de Compostela: Universidade de Santiago de Compostela.

Richardson, R. J. (1999). Pesquisa social-métodos e técnicas. São Paulo: Atlas.

Rifkin, J. (2000). La era del acceso: la revolución de la nueva economía. Barcelona: Paidós.

Rosas, A. (1987). Universidade e criatividade. Anais do VII Seminário Nacional sobre Superdotados. Rio de Janeiro: SENAI, pp. $|2|-\mid 24$.

Silva, O. J. \& Alencar, E. M. L. S. (2003). Criatividade no ensino de enfermagem - enfoque trísdico: professor, aluno, currículo. Revista Brasileira de Enfermagem, 56, 610-6I4.

Sousa, F. C. (2006). A criatividade na formação de professores. Disponível: www.anhembi.br/forumpermanente/files/acriatividade-na-formacao-de-professores-sousa.doc. Recuperado: 24 set. 2006.

Sternberg, R., \& Lubart, T. (1996). Investing in creativity. American Psychologist, 5 I , 677-688.

Tardif, M. (2003). Saberes docentes e formação profissional. Petrópolis: Vozes.

Tibeau, C. C. P. (2002). Entraves para a compreensão da criatividade no ensino e na formação do profissional de educação física. Lectura: Educación Física y Deportes, 5I. [Online]. Disponível: http://www.efdeportes.com/efd5 I/criativ.htm. Recuperado: 20 ago. 2005.

Uano, L. M. (2002). La creatividad? Un talento exclusivo de los artistas o una capacidad de todo ser humano? Linhas Críticas, 8, 265-287.

Vallejo, J. M. B. (2003). Escola aberta e formação de professores. Rio de Janeiro: DP\&A.

Vygotsky, L. S. (1930/1987). Imaginación y el arte en la infancia. Cidade do México: Hispânicas.

Wechsler, S. M. (200I). A educação criativa: possibilidade para descobertas. Em: S. Castanho \& M. E. Castanho (Orgs.), Temas e textos em metodologia do ensino superior (pp.165170). Campinas: Papirus. 
Wechsler, S. M. (2002). Criatividade: descobrindo e encorajando. Contribuições teóricas e práticas para as mais diversas áreas. Campinas: Livro Pleno.
Zabalza, M. A. (1998). Qualidade em educação infantil. Porto Alegre: Artmed.

Recebido em: 04/06/2007

Revisado em: 14/I2/2007

Aprovado em: 17/12/2007

Sobre as autoras

Zélia Maria Freire de Oliveira (zeliafreire@gmail.com) - Universidade Católica de Brasília - Mestre em Educação Endereço para correspondência:

SHIS QI 13, Conjunto 13, casa 03, Lago Sul, CEP 7I.635-I30 Brasília - DF

Eunice Maria Lima Soriano de Alencar (ealencar@pos.ucb.br) - Universidade Católica de Brasília - Psicóloga, Ph.D. pela University of Purdue nos Estados Unidos e professora do Programa de Mestrado em Educação da Universidade Católica de Brasília.

Endereço para correspondência:

Programa de Mestrado em Educação - Universidade Católica de Brasília

SGAN 916 Módulo B Asa Norte, CEP: 70.790-160 Brasília - DF

Telefone: (6I) 3248-5539 